\title{
VR as Library Technology: Early Faculty and Student feedback on Educational Use of Immersive Technology
}

\author{
V. J. McClendon, Bellevue College \\ Library and eLearning, 3000 Landerholm Circle, Bellevue, WA 98007 \\ (425) 564-3056; vivienne.mcclendon@bellevuecollege.edu \\ James Riggall, BitLink \\ Launceston, Tasmania, 7250, Australia \\ +61409149651; james@bitlink.com.au
}

\begin{abstract}
In developing a Virtual Reality (VR) project, the library creates a democratic home for a teaching and lab space for a visiting Fulbright scholar to build energy and community around this new immersive technology. Following three academic quarters of VR teaching, workshops, community outreach and awareness building, interviews of volunteer faculty and student participants provides valuable feedback on their reflection as to the potential of Virtual Reality experiences to scaffold and supplement student learning and their value of the positioning of such technology within the library as a central location. Faculty $(\mathrm{N}=5)$ each provide unique lenses on the importance of the immersive technology within their areas of practice. In addition, two advanced students in the paired Communication Studies VR courses discussed their experiences. Advanced students explained after intensive use of VR software and final project development, the experience changed their thinking about education and future career opportunities. Additional pre-medicine students provided written reflective responses following a VR biology experience $(\mathrm{N}=13)$. Future study is recommended to explore the library as a technology hub and further nuanced details of how immersive technology can expand and scaffold student learning outcomes across a variety of subject areas.
\end{abstract}

\section{Key Words}

Virtual Reality, Libraries, Learning, Technology, Virtual Experience

\section{Introduction: VR as Library Technology}

In the last four decades, computer technology has rapidly transformed the way we work and communicate including the newest Virtual Reality and Augmented Reality tools. In that same period, libraries have been evolving and transforming from vast areas of book storage and quiet study to today's vibrant, interactive, social learning environments (Mathews, et. al, 2018). Libraries provide a safe central location for exploration of materials, ideas and technology. Recently, some libraries are recasting their roles "in terms of the broader, more encompassing framework of technical facility, information literacy, and digital creativity" (Becker, et. al, 2018, p. 27). There, physical and electronic resources are accessible but in addition, libraries provide critical instructional personnel who deliver basic how-to scaffolding as well as deeper critical thinking and expert knowledge support. Libraries act as ramps, "lowering the barriers to entry and reducing fear and anxiety" (Mathews, et. al, 2018, p. 53).

As a central recognizable location, libraries exemplify a safe, neutral, democratic location for resources and materials, free of presuppositions of majors, prequisite knowledge or 
assumptions of ownership of valuable and limited resources on college campuses. Indeed, libraries as a whole are seen as the most singularly democratic institution in the United States. Rotarian Magazine praises the library as "...the only place where people of all colors, creeds, ages, and political beliefs freely, easily and inadvertently intermingle" (2015, p. 26). It is also noteworthy that libraries have become one of the most common contexts in which many people access technology tools, in particular, experiencing new, immersive technologies (Ford, 2017; Lambert, 2016; VarLibraries, 2017).

\section{Fulbright Goals and Activities}

The goals for the Fulbright scholar included teaching two communication studies courses on immersive technology, developing lasting connections through community outreach and partnerships, creating professional enrichment for college faculty through the co-creation of innovative pedagogical practices, and ensuring the sustainability of strengthened and institutionalized relationships between the college and local organizations and tech industry.

Another critical element to the work was the course placement within communication studies, a non-technical area of study to learn about new communication technologies open to all students as an elective. The first course was a survey and introduction into immersive technologies history and development up to the present moment. This course not only documented the development of immersive technology and software development but incorporated guest presenters involved in creating research, software, and hardware over that same period. The second course served as a hands-on laboratory experience requiring students as a final deliverable to develop a VR prototype in Unity, a game development platform that enables students to build virtual reality experiences, and write a paper in which they reflect on what they learned through their experiences in the course. This type of situated learning with educational technology is designed to support complex learning and professional competencies. "These stress the collaborative construction of knowledge through active learning ("social constructivism") and the importance of higher-order skills such as problem solving, learning strategies and self-regulation" (Jochems, van Merrienboer, \& Koper, 2004, p. 1).

Another goal of the class and the other scholarly activities was the creation of community beyond the geographical region. One way that was facilitated in the class was through connections in the US and abroad. This program was developed as a kind of experiment, where the scholar connected classrooms even across international borders. While the core group of students were co-located at the college, many other students and participants logged into the course from across five or more US sites and three more in Australia. Throughout the course, students were to meet and interact with students and leaders from another part of the world via technology in and out of class time.

A key element was the location of the scholar's activities within the library as a central, open to everyone, democratic space. In this selection, the library shared a place that is both public and private, bridging a variety of space needs for a campus and a community. In creating a community of practice, the library allows the special blend of resources, people and spaces that invisibly support the development of connections. Indeed, Rasmus and Salkowitz note that today's students are uniquely ready to be "next-generation workers... as they come to the workforce with strong skills in collaboration, entrepreneurial instincts, and expectations of dynamic change and transparency" (p. 14, 2009). The Fulbright VR project leveraged the library as an open educational hub for just-in-time learning driven by the interests of the learner as described by Rasmus and Salkowitz (2009). The VR project allowed contextualized 
collaboration with a variety of community and industry experts with the blending of multiple interfaces, communication technologies, modeling and simulation, all readily available in the library.

As a part of project evaluation, data collection was necessary to gauge participant reaction to VR as a new learning tool, both in terms of its potential for student learning as well as the logistics of using the hardware and software. To that end, the authors propose the following research questions:

- Does early faculty and student interview and reflection data support the conclusion that Virtual Reality experiences scaffold and supplement student learning?

- Does the interview data reveal actionable findings to help shape the development of an XR lab within a library setting?

\section{Methods}

In selecting methods for this study, there were several considerations: the epistemological assumptions of the researcher; the nature of humans in learning and evaluating new contexts and tools, and given the newness of the technology, time to ensure participants could adequately reflect on their experience. In theoretical context, we as researchers, teachers and learners must decide how we come to know things and thus how we assume others come to know things. Constructivism has its basis in social learning theory which asserts that life as a lived experience is "constructed socially by individuals" (Merriam, 1998, p. 4). This epistemology also rests on social learning theory from education, such as Vygotsky (1980), Bruner (1990), and others who built on the idea that individuals experience learning within the lived context. These are the assumptions upon which the research rests.

In addition, the newness of immersive technology results in what is termed the 'wow effect' which may skew participants reactions (Moore, 1996). Coupled with the small number of participants dictated by the limited availability of personnel and equipment, a qualitative approach was selected as an appropriate evaluative tool to illicit descriptive data. In this research study, I used a set of semi-structured interview questions (see Appendix) but expected the interviews to tend toward the informal and unstructured end of Merriam's interview continuum (p. 73) in order to allow the interviewees an opportunity to construct their own meanings about the tool and its locale.

Participants were given the interview questions in advance of their interview. Most of the interviews were conducted individually except in two cases. Vito and Joey opted to interview together as did Jean and Ricardo, the advanced students due to scheduling problems. All participants are identified by pseudonyms. Interview data was analyzed to identify recurring themes which are demonstrated below.

\section{Data Analysis}

\section{Faculty Interviews}

Faculty who were interviewed were volunteers from among those who had taken part in any of a variety of VR related activities and events during the three academic quarters encompassing the Fulbright scholar visit. Their instructional areas included Communication Studies, Interior Design, the RISE Learning Institute (Research, Innovation, Service and Experiential Learning), and Biology (pre-med). The following provides highlights of the interviews based largely upon the emerging themes of personal experience with VR, perceived 
value of VR in a teaching and learning context and the role of the library as a possible element in the VR experience and scaffolding quality.

\section{Gary}

Gary has over 20 years teaching experience in communication theory with hands on activities. He began his work many years ago prior to the digital age with digital visualization tools and multimedia work. Regarding the value of VR to the teaching and learning experience, he states,

In the best possible light, it addresses human cognitive processes. Tom Furness called [VR] bandwidth to the brain, but I think it's not just the brain, but our entire body [that] becomes engaged. So, the intelligence and the capacities of who we are as a multisensory body now have a place to be expressed.

He is impressed with what VR means for time, space and place. The ability to become small, or to compress time are tools never before available to instruction in real time. Regarding the role of the library, Gary feels the location was pivotal to the program thus far. He notes, "as a resource for experiences you can't get anywhere else [on campus], but from the library." Gary also thinks the placement is not accidental, reflecting that, "this is taking place within the library which is a nexus of information exchange." Beyond the individual experience, he is very excited about the potential for networked VR as a social space as the key to building a larger XR community. Gary notes, "the crux of it is how people can truly work together collaboratively without being physically co-located."

\section{Sara}

Sara has over 20 years' experience in teaching and leading instructional departments. Her area is Communication Studies which she explains is a melding of several older program areas "including mass media, new media, communications, and film so we definitely see a place for VR in our program. Our work is a little about technical application but mostly we look at theory and application." In Communication Studies, "we focus on how we can best equip our students to be effective communicators in this new [technological] setting. She has no previous personal experience with VR but she's seen kids at the mall playing on machines or on their cell phones in very distracted and distracting ways in public. As a result of the VR programming in the library, she has had her first experience with VR and was struck with not only how the technology might be employed in her own program but across campus. She remarked, "I just thought, oh wow, this is something big. And what a time when it is just taking off and becoming more available to the general public. It could be used to introduce students to architecture. Not just architecture but space and how we might interact in that. This is so different than a diagram or even a 3D model. What a new way for students to access information!" In terms of the role of the library, Sara felt that it was a great location and openly available to everyone. Its location provides a benefit to the entire campus due to the space but also the staff who support the technology. Sara's demonstration showed her that the tool still needs scaffolding for both students and faculty, at least initially. Regarding teaching and learning, Sara recalled thinking it applied in so many contexts across campus and, "we actually threw this around in a department meeting this fall. Somebody brought up all the students we have in public speaking. Are there ways to help students deal with speech anxiety" as a powerful teaching and psychological tool. She does note 
that while the technology is cool currently, it has the potential for allowing individuals to further remove themselves from other human beings. Yet she comments, she believes that "technology is not inherently good or bad, it's how we choose to use it."

\section{Vito}

Vito teaches of Anatomy and Physiology I and II, as well as microbiology primarily to nursing and other pre-med students at the college. He has experienced a brief 10-minute demonstration of a VR game from his son prior to being involved in the Fulbright VR program. Vito's interest was piqued by the experience and did a bit of research to find out what others identified at the strength of VR. He notes, "It was seeing things differently. Just seeing how the muscles of the arm work. You can talk about it in class but seeing it is entirely different. That is the strength of VR." Vito was inspired by his experience and the research into VR's 3D ability. He also commented on the immersion factor. "VR is cutting you off of external stimuli. In a class, we typically have so many external stimuli. The cell phone is a constant distraction. When you have on a headset, you are either completely engaged or you are daydreaming." He goes on to explain why the 3D visualization is so critical in the medical field, "that's the major difficulty in anatomy and physiology is to see the 3D. In MRIs, the different cross-sections give very different images. It is so difficult for students to understand." But in VR, he explains, "it's like taking a cadaver [and] taking a cross section.". In addition, Vito describes his extra credit activity for students as a bit of a longitudinal study on supplemental support for student learning:

I have tried many things to see what works best for my students, you name it from different publishers. No matter what I've tried, you know, you get 70/30 percent positive. So, this has been the only tool so far that all of the replies, not a single person said that this was not useful. My [required] limit on extra credit was 15 minutes but students stayed a long time. Engagement, retention of information, and now it seems critical... is the knowledge to develop the ability to question... That's critical thinking. There's a lot of potential in that.

Being so moved, Vito was driven to reach out to local VR software development companies offering to work as a subject matter expert in developing a series of anatomy and physiology segments. He would like to create at least one VR module for each of his instructional sessions. He goes on to explain how critical the ability to see in $3 \mathrm{D}$ is not only in terms of medicine but in terms of the ability of such foundational mental pictures in the schema students depend upon for the rest of their college career. Vito explains, ultrasounds are very hard to see and make out individual organs in relation to each other, for example, the thyroid commonly obscures the carotid artery. Initially students do not have a mental picture of the location of these organs before starting to look at ultrasounds leading to further confusion. The key, he explains, is:

"the way that the brain works, it memorizes things based on the experience and it forms certain pathways and follow up is built on that pathway. If I had thought of this as a stapler or an apple, so then later on when people talk about apple or stapler, it is there, it is part of the design, so I start to put things together. You don't know it is there, but it is there. If the mnemonic is wrong then I have the wrong pathway. It doesn't make sense; people make fun of you for always for getting it wrong - cutting the carotid artery. But in 
my mind, I think I have the right image. In 3D it is really built up and I have a clear picture in my mind.

Despite his excitement, Vito recognizes there are growing pains with the technology. In particular, for people who wear glasses, the headset either keeps you from wearing them or causes them to press into the head and sit at odd angles. This makes reading pop-up explanatory notes hard, or impossible to read.

Lastly, Vito feels strongly that placement in the library is perfect for his needs. He cannot imagine using the technology inside the actual classroom in its current configuration and level of development. Rather, Vito believes it is currently best suited as a lab or supplemental experience with support for his students.

\section{Joey}

Joey has held a number of positions at the college over the years including instructor and now as a director in an experiential learning lab. He continues to work closely with students in hands-on supplementary activities, particularly for STEM students. Joey is also technology savvy and has a great deal of experience with personal computers and gadgets like robots; he has played a central role in setting up a maker's space on campus. In their STEM to STERN program, his unit has had students use VR in their projects; a few interior design students also attempted VR exploration. However, lacking adequate HMDs and matching computers, it was a challenge. They were forced to substitutes like Google's Daydream VR. Joey recalls, "those are great and allow you to see a little bit of the 3D content but they are not the really immersive experience where the student is really cut off from the outside world. It adds a little dimension to it without it being fully immersive. So, having the equipment this year has been a bit of a game changer..."

From a teaching and learning perspective, many of his students hope to become software or hardware engineers. In his opinion, "for them VR is not all that much of a game changer, it is a new technical tool like a new language or another tool, it's new and it's cool, but it's not fundamentally different than many other technical tools." However, there are students who find VR a sea change in their academic project creation ability. Joey remarks that, "the students who are aiming for the design majors like interior design, architecture or even engineering drafting, VR enables them to do things that they were struggling with before. The element of visualization and seeing 3D and thinking 3D in a way that is intuitive and then being able to translate that back into a CAD program is a game changer.” In the Fulbright Plan Jam event, interior design students were able to see their work in 3D with all of them in the same virtual space simultaneously. These students were able to move and change elements on the fly in minutes rather than hours in programs like Google Sketchup, thus enabling a level of teaching and learning that simply was not possible before. Joey recalls, "the rapid improvisation and rapid changing in thoughts and perspective in a shared collaborative way... was pretty cool to see. For me, it's a great logical extension of things that are happening in some of the technical professions, and is pretty revolutionary." He also sees powerful application in medical imaging. Joey ends by reflecting, VR's "potential applications for... beginning students and beginning to thinking about to see it and control it and manipulate it themselves is, well it's a game changer in the student mind. It's powerful stuff." 
Eric

As an interior design professor, Eric has worked in industry and had a great deal of exposure to technical specifications, tools for rendering images, and other productivity tools related to his industry. And though Eric was well aware of VR being used in high-end firms in the US, he has not had any personal experience with VR. In fact, he was somewhat skeptical of its use, perhaps due to the logistics of asking students to learn yet another piece of software. Yet, he notes, that it is not uncommon for an interior design graduate to be hired in a firm simply because $\mathrm{s} / \mathrm{he}$ is familiar with a new piece of software the firm would like to be proficient at. In attending the Plan Jam event, Eric readily admits he was happily surprised at the ease with which his students were able to import images into VR software. He recalls,

I became convinced of the powerful value of the tool. My students typically have to stop the design phase 10 or 12 weeks prior to the final due date in order to do all their renderings from the CAD program. That weekend they were able to take their work, import it into the program and see things in 3D. They knew immediately if something was wrong with the design. Not only that, they could change things as they were working in groups.

In the immediate future, Eric does not foresee VR working in his classroom due to the logistics of space and set up time, as well as hardware and software considerations. But having this capacity in the library, he notes, represents significant headway. The placement allows the tools to be used as lab event or perhaps even a longer class time. Interior design students can truly see their work and collaboratively make changes in real time with VR. It is possible now for students to design up to a few days before the final project deadline if adequate equipment and support were available to sustain the numbers of students enrolled in his interior design classes.

\section{Advanced Student Interviews}

Advanced students were those who took part in both VR courses taught during the winter quarter of 2018. Among students enrolled in the two VR communication studies courses offered, two students volunteered for in-depth interviews regarding their participation and reflection on the VR project.

\section{Jean}

Jean is a non-traditional student who has over 10 years teaching experience as a teacher's aide in early childhood education which fostered an interest in "how people learn and how to explain things to them." She has had extensive experience in after school programs, tutoring and other educational contexts. Additionally, she has previously completed a number of math and computer science classes prior to enrolling in the VR communication studies classes. Jean had dreamed of connecting her love of education with her growing interest in computers science by building games for math concepts, and putting those on the web as a way to help motivate learners. During her time in the VR classes, Jean sought and found a mentor and development partner from Australia, one of the course partner sites. She recounts that she is proud of all she learned, in large part, due to her self-directed project. With her mentor and other student collaborators, Jean was able to create a program in Unity designed to teach calculous through the throwing of objects and using formulas to adjust trajectories. 
"It's a matter of pride, in a class like this with brand new technology, we're literally creating... literally creating things that can be released and that can help other people. It's more enjoyable than just the dusty ol' 'do a four loop' that's in your traditional computer science classes."

Interestingly, Jean had had previous experience with VR gaming via a personal friend who worked for Oculus. She "thought that looks very cool, but I have no idea; this is magic, I'll never learn it." The gaming previously did not interest her despite her computer science program focus. Jean even attended a young developers panel discussion hosted by the Fulbright scholar; again, it was interesting but not inspiring. Jean recalls,

The life changing moment, I can pinpoint that moment, was when I was in the room and first to try the VR environment called theBlu... I put the headset on and suddenly I was in the water. And what I didn't tell him was that I'm terrified of deep water. I completely lost the sense of being in the world... and almost fell down. Nothing compares to standing on a boat and seeing a full-sized whale staring at you.

Jean's experience was so immersive, so transformative, she immediately started helping others use the VR equipment. She has since purchased a VR compatible computer and intends to continue to program and develop for VR. Previously she had dismissed VR because it was too expensive and the programming was intimidating. "And now I want to shout it on the rooftop, 'hey everybody, there are Vives on campus that you can go program!" Jean now owns a computer that is VR capable. And her self-talk has dramatically changed. "I've been telling everybody, I'm a computer science student with a VR focus. I am going to continue to work on [my] project and VR applications. Let's see what I else I can do."

Regarding the project library locale, it seems location was critical to Jean. She explains,

I was able to try something that was out of my radar due to expense. I was able to try it, fall in love with it, and step into it. I wouldn't be able to do this without being in a program that not only provided the lecture, but also provided the equipment, that also provided the mentorship, that also provided the lab time, and so on."

All of that was possible because it was in the library, with support and open to all students. Jean sees bright possibilities for VR in education through collaborative learning across distant locations if the challenges of funding, teacher training and infrastructure support can be solved. The strengths of VR are its visuals and simulation abilities. She also believes it holds a great deal of promise in social VR software as more humanizing and less "freaky" that chat rooms due to avatars and voice capabilities. Jean emphatically stated, "VR is not just a platform, it's an experience!"

\section{Ricardo}

Ricardo is a pre-med post-baccalaureate student, electric with energy and excitement for many things including VR. As a pre-med student, he never thought about computers related to his career, but now he says, "it actually makes so much sense, it's ridiculous!" Ricardo needs to improve his grades to get into the medical school of his choice so he just happened to be in the library and saw the signs for VR and met James. After a tour of the eye, he remarked, "I was so 
excited, this is some next level stuff!" In his irrepressible way, Ricardo now wants to create VR experiences to every organ and every molecule and every atom in the body. He states,

"I want a 'magic school bus ride' inside of people in VR. Performing simulations is the way to do it. It's the broadest densest most information fire hose method you can get it by and that's what we need in schools. Yeah!"

Ricardo is taking Organic Chemistry and recognizes how useful VR visualizations could be to his fellow students. He is very impressed with new content provided by PYRUS Medical VR of recordings made inside living humans to illustrate illness, surgery, and other details. Despite this great excitement, Ricardo had no previous experience or interest in VR. "It's like a whole new world. It's the difference between not being connected to the internet 24-7 versus today. How do you quantify that? I have the world at my fingertips now!" He clearly recognizes that the library location played a critical role in his discovery of the VR Project. He reflects, "The fact that [the class] is open to everyone, 'cause I wouldn't be able to have access if you needed to be a CS student, right? I'm pre-med. But I found it because it is open to all students from everywhere."

Regarding the strengths of VR, he, too, mentions scale, and movement, but he clearly feels there is something more elusive, "it's like another dimension has opened. I don't know how to describe it." But Ricardo is confident that VR is the most important educational tool he has ever experienced. He is also convinced, after having lunch with one of the principals at HTC Vive, that there are no insurmountable obstacles and the market is about to "literally explode."

Despite many hours of exposure to VR and even developing simple programs in Unity for the class, both Jean and Ricardo are its greatest supporters and fully endorse the support and program development that have gone into the Fulbright project resulting in their involvement and classroom success.

\section{Student Reflections}

Student reflection data was gathered with the support of a Biology faculty member who awarded extra credit for post-lab reflections as a normal part of his teaching. The VR reflection entry represented only one of many diary entries submitted for extra credit. Thirteen students provided the instructor with a reflection after experiencing two to four VR environments and agreed to participate in the study.

The reflective activity allowed students to consider the benefits of VR as relates to better understanding, further elaborating, or better visualizing minute, intricate, or complex data. A number of the student recognized their own needs in mastering human biology information. However, it was also quite clear that students were experiencing the wooed by the novelty with a large number of comments like: "freaking amazing," "super fun," "engaging," "super cool," and "incredible."

Yet, there were notable in-depth reflections indicating an understanding of both the subject and how the software could assist learning as recorded in the following statements:

"As a visual learner, [VR] can help [me] to understand complex subjects and theories such as anatomy and physiology."

"I loved everything about this [activity], especially, the muscle system because it is more detailed than other systems...I wish I were able to stay longer." 
"I was able to get a better sense of how the components of the cells interact with their environment. From the book, "it is difficult or impossible to conceptualize or visualize the processes holistically."

"I concluded that VR is a great supplement to learning and memorizing anatomy and physiology... The voyage into different organs made it possible to stay engaged and focused."

Student feedback from the biology/pre-med group was universally positive, perceiving VR as an excellent supplementary experience to deepen and further elaborate on existing classroom knowledge. Interestingly a number of students also recognized the logistics of current VR technology may to complex and slow for actual classroom use, stating that while they would enjoy having such technology in the classroom, it would take too long to set up and have everyone go through the experience. The promise of VR collaborative software development may soon allow groups to experience the same environment simultaneously, thus classroom applications may quickly be within reach.

\section{Discussion}

All participants listed attributes about the VR environment that amazed them or at least won them over as a tool that can positively support student learning. Generally, participants recognize the strengths of VR as an educational tool as:

- visualization,

- in scale,

- extreme reality,

- simulations, and

- the potential for active, design-based learning.

Specifically, faculty shared some concern about VR in its current level of development as an immediately deployable classroom tool. All five faculty members interviewed gave in-text examples or explicitly pointed out that VR currently works best as a lab or supplemental tool due to its complexity and logistics.

These rich interviews let us know there are actionable items that need to be addressed:

- procuring more equipment

- continuing support for faculty and students

- developing processes to handle workflows reducing wait-times

- offering workshops for faculty and students to build greater awareness

- offering coding instruction for faculty or students to develop VR experiences, and

- continuing to listen to XR participants about evolving needs.

Through the rich and textural data, we hear the voices of faculty and students across many majors, seeing potential for VR on a college campus at the center of a VR technosphere.

\section{Limitations}

The interviews representing the bulk of the data presented in this study were performed at the end of the spring quarter approximately four weeks after the quarter was completed. Iterative interviews performed at benchmarked times may provide greater insight into teaching practice and student reflection, might provide some balance for the 'wow effect' noticed among some student responses. 


\section{Future Studies}

Though the data set consisted of seven interviews and a set of thirteen student reflection entries, the results were quite rich. More analysis is possible to more clearly connect the perceptions and assumptions of the participants with next steps for the completed Fulbright project, now a new XR Lab. For example, it may be possible to better identify faculty epistemologies and chart the assumptions about the utility of immersive technologies based on those beliefs. Words might be identified which layer in meaning; these could be better elucidated in a follow-up interview with probing questions.

Adding to this foundation of original data, future iterations of the study will help begin to build a broader, more contextualized sense of faculty, their areas of practice and their willingness to try new immersive technologies. On-going interviews may also allow the researchers to track the awareness building across campus and its impact and the importance of location in a democratic, open access location such as a library on the success of the project. Additional tracking of student academic majors and interviews may shed more light on the value of a democratic space for providing a ramp to technology career to women and underserved populations.

\section{Acknowledgments}

The authors would like to thank the Fulbright Visiting Scholar Program (2017-18) for its support and contribution to the Bellevue College VR Fulbright project and the selection of Mr. James Riggall as the visiting scholar.

\section{References}

Becker, S. A., Brown, M., Dahlstrom, E., Davis, A., DePaul, K., Diaz, V., \& Pomerantz, J. (2018). NMC Horizon Report: 2018 Higher Education Edition. Louisville, CO: EDUCAUSE.

Bruner, J. (1990). The Jerusalem-Harvard lectures. Acts of meaning. Cambridge, MA, US: Harvard University Press.

Ford, A. (2017, September 1). Making virtual reality a reality: NCSU libraries offer top-notch simulation technology. American Libraries. Retrieved from https://americanlibrariesmagazine.org/2017/09/01/making-virtual-reality-a-reality/

Jochems, W., van Merrienboer, J. \& Koper, R. (2004). Integrated E-Learning: Implications for Pedagogy, Technology \& Organization, New York: Routledge-Falmer.

Lambert, T. (2016, February 24). Virtual library: Creating a new experience. Public Libraries Online. Retrieved from http://publiclibrariesonline.org/2016/02/virtual-reality-in-thelibrary-creating-a-new-experience/

Mathews, B., Metko, S., and Tomlin, P. (2018, May/June). Empowerment, experimentation, engagement: Embracing partnership models in libraries. EDUCAUSE Review.

Merriam, S. B. (1998). Qualitative research and case study applications in 
education. San Francisco: Jossey-Bass Publishers.

Moore, G. (1996). Technology and social communication. Technology in Society, 18(2), 253260. Retrieved from https://doi.org/10.1016/0160-791X(96)00002-4

Rasmus, D. \& Salkowitz, R. (2009). Microsoft executive leadership series: Listening to the future: Why it's everybody's business. Hoboken, NJ: John Wiley \& Sons, Inc.

Anonymous. (2015). In praise of libraries. Rotarian Magazine, 25-29.

VarLibraries, 2017. VarLibraries: Building an immersive learning community. Retrieved from http://www.varlibraries.com/

Vygotsky, L. S. (1980). Mind and society: The development of higher psychological processes. Cambridge, MA: Harvard University Press. [Edited by M. Cole, V. John-Steiner, S. Scribner, and E. Souberman].

\section{Appendix}

\section{a. Simi-Structured Interview Questions for Faculty}

- What is your name and what discipline(s) do you teach in?

- What was your experience with VR before it became available in the library? Is there any advantage to this location?

- Now that you've had a chance to experience VR on campus, has your view of VR changed and if so, please explain?

- What do you think is the greatest opportunity or strength of VR in your own academic discipline?

- How do you think VR might change the way teaching is done or students learn in your discipline over the next 5-10 years?

- Do you have any concerns about the impact of VR on teaching and learning (particularly in your own discipline(s)? What are the things that concern you, if any?

\section{b. Simi-Structured Interview Questions for Advanced Students}

- What is your name and what discipline(s) do you study in?

- What was your experience with VR before it became available in the library? Is there any advantage in this location?

- Now that you've had a chance to experience VR on campus, has your view on VR changed and if so, please explain?

- What do you think is the greatest opportunity or strength of VR in your field of study? 
- How do you think VR may change the way teaching is done or students learn in your field of study over the next 5-10 years?

- Do you have any concerns about the impact of VR on teaching and learning particularly in your field of study? What are the things that concern you, if any? 